\title{
Neoadjuvant chemotherapy increases rates of breast-conserving surgery in early operable breast cancer
}

\author{
Vivian CM Man, Polly SY Cheung *
}

This article was published on 9 May 2017 at www.hkmj.org.

\section{A B S T R A C T}

Introduction: Neoadjuvant chemotherapy is commonly used in stage III breast cancer for disease down-staging. Its use has now been extended to early breast cancer to increase the rate of breastconserving surgery. This study aimed to evaluate the effectiveness of neoadjuvant chemotherapy in early operable cancers.

Methods: A retrospective study was carried out at the Hong Kong Sanatorium \& Hospital of 102 patients with stage I to III primary breast cancer. All patients who underwent neoadjuvant chemotherapy followed by definitive breast surgery between January 2004 and July 2013 were included. Their pathological complete response and rate of breast-conserving surgery were studied. Data were compared using Chi squared test and Student's $t$ test.

Results: After neoadjuvant chemotherapy, 23\% of patients achieved a pathological complete response, of whom $80 \%$ had human epidermal growth factor receptor 2 (HER2)-positive disease or triplenegative disease. Hormonal receptor negativity was associated with a higher pathological complete response rate $(\mathrm{P}<0.05)$ that was in turn associated with a higher likelihood of breast-conserving surgery $(\mathrm{P}=0.028)$. Patients with stage II disease were more likely to convert from mastectomy to breast-conserving surgery following neoadjuvant chemotherapy.

Conclusions: Neoadjuvant chemotherapy is a useful treatment to downsize tumour in early breast cancer, thereby increasing the rate of breast-conserving surgery. It is especially effective in patients with HER2-positive/oestrogen receptor-negative disease or triple-negative disease.
Hong Kong Med J 2017;23:251-7
DOI: $10.12809 / \mathrm{hkmj} 164972$
${ }^{1}$ VCM Man, MB, BS, MRCS
2 PSY Cheung *, FCSHK, FHKAM (Surgery)
1 Department of Surgery, Queen Mary Hospital, Pokfulam, Hong Kong 2 Breast Care Centre, Hong Kong Sanatorium \& Hospital, Happy Valley, Hong Kong
* Corresponding author: pollyc@pca.hk

New knowledge added by this study

- Neoadjuvant chemotherapy for breast cancer can downsize the tumour with a consequent higher rate of breastconserving surgery, especially in patients with human epidermal growth factor receptor 2-positive/oestrogen receptor-negative disease or triple-negative disease.

Implications for clinical practice or policy

- Neoadjuvant chemotherapy is a useful alternative in early breast cancer for women considering breastconserving surgery.

\section{Introduction}

Breast cancer is the leading cancer affecting women in Hong Kong, followed by colorectal and lung malignancy. ${ }^{1}$ The number of new breast cancer cases in Hong Kong has tripled since the 1990s and the lifetime breast cancer risk in women is currently one in $17 .{ }^{1}$ Among the 12345 patients studied in the cohort of the Hong Kong Breast Cancer Registry from 2008 to February 2014, 55\% were diagnosed with stage II disease or above and $5 \%$ of the cohort received neoadjuvant chemotherapy. ${ }^{1}$ This cohort of patients is estimated to cover approximately $40 \%$ of patients reported by the Hong Kong Cancer Registry of the Hospital Authority.

Neoadjuvant chemotherapy has played an increasing role in the management of breast cancer over the last few decades. It was considered at least as effective as postoperative chemotherapy in terms of disease-free survival (DFS) and overall survival (OS) in the National Surgical Adjuvant Breast and Bowel Project B-18 trial. ${ }^{2}$ Neoadjuvant chemotherapy allows disease down-staging, thus increasing the probability of successful breast-conserving therapy. ${ }^{3,4}$ In addition, tumour response can be monitored 'in vivo' and chemotherapeutic regimens modified accordingly. Studies have also suggested its role in disease prognostication, especially the presence of pathological complete response in highly proliferative tumours. ${ }^{3}$

The aims of this study were to identify 


\section{新輔助性化療為可開刀的早期乳癌患者增加保乳 手術的比率 \\ 文芷薇、張淑儀}

引言：新輔助性化療被廣泛用於治理第三期乳癌以降低癌期, 這種方 法現已延伸到早期乳癌患者來達至增加保乳手術的比率。本研究評估 新輔助性化療對可開刀的早期乳癌患者的效用。

方法：本研究對象為香港養和醫院第一至三期的 102 名原發性乳癌患 者, 她們均於2004年1月至2013年7月期間接受新輔助性化療後再接 受乳房手術, 並研究患者病理完全反應 (即病理報告完全看不到乳癌 病灶) 和保乳治療的比率。研究使用卡方檢驗和學生 $t$ 檢驗比較所得數 據。

結果：患者中有 $23 \%$ 達至病理完全反應, 當中八成患者為HER2陽 性乳癌或三陰性乳癌。雌激素受體 ( ER ) 陰性與較高的病理完全緩 解率相關 $(\mathrm{P}<0.05)$, 而這與較大保乳手術的可能性相關（ $\mathrm{P}=$ 0.028 ）。第二期乳癌患者接受新輔助性化療後, 乳房切除術轉換為 保孚手術的機會較大。

結論：新輔助性化療是降低早期乳癌癌期的有效治療, 從而增加保乳 手術的比率。這種治療在HER2陽性或ER陰性乳癌的患者中尤其有 效。 recruited patients had their surgery performed by CSY, who is one of the breast surgery specialists at the hospital. Patients were followed up perioperatively in the out-patient clinic of CSY. Patient demographics, pre-chemotherapy and post-chemotherapy disease staging, tumour characteristics, positron emission tomography-computed tomography findings, and prescribed chemotherapeutic agents were evaluated.

Effectiveness of neoadjuvant chemotherapy was assessed in two ways: presence of pathological complete response and the feasibility of breastconserving surgery after chemotherapy. Intrinsic tumour characteristics that influenced treatment response were analysed. Tumour size, nodal status, tumour grade, hormonal receptor status, human epidermal growth factor receptor 2 (HER2) receptor status, Ki67 level, and chemotherapeutic agents used were the independent variables in this study. Statistical analysis was performed with SPSS (Windows version 20.0; IBM Corp, Armonk [NY], United States) and a P value of $<0.05$ was considered statistically significant. Univariate analysis was performed with Student's $t$ test and Chi squared test where appropriate. Definitions of various terms used in this study are listed in the Appendix.

\section{Results}

possible tumour characteristics that may benefit from neoadjuvant chemotherapy and to evaluate the effectiveness of neoadjuvant chemotherapy in increasing the rates of breast-conserving surgery in early operable breast cancer.

\section{Methods}

This was a retrospective study carried out at the Hong Kong Sanatorium \& Hospital and approved by the hospital research committee in September 2013; the requirement of patient informed consent was waived because of its retrospective nature. This study was done in accordance with the principles outlined in the Declaration of Helsinki. All patients with breast cancer who underwent neoadjuvant chemotherapy followed by definitive breast surgery from January 2004 to July 2013 were recruited. The choice of definitive breast surgery, either breastconserving surgery or mastectomy, was determined by an experienced breast surgeon (CSY) and based on the oncological and cosmetic outcome of each patient. Patients who presented with distant metastases and those who underwent neoadjuvant hormonal therapy were excluded. Those who had stage IV disease were also excluded.

Patient records were retrieved from the breast cancer database at the Hong Kong Sanatorium \& Hospital and out-patient clinic of one of the authors (CSY) by an independent research assistant who was blinded to the study hypothesis and outcome. All

\section{Patient's characteristics}

From January 2004 to July 2013, 2156 patients underwent breast cancer surgery at Hong Kong Sanatorium \& Hospital by an experienced breast surgeon (CSY). Stage II or III disease was diagnosed in $48 \%$ and 105 (5\%) of all patients underwent neoadjuvant chemotherapy. Three patients were excluded due to significant missing data. A total of 102 were ultimately recruited.

Characteristics of patients are summarised in Table 1. Almost all recruited patients had stage II or III disease before commencement of neoadjuvant chemotherapy. Invasive ductal carcinoma constituted more than $90 \%$ of all diagnosed breast cancers. One quarter of the recruited patients had triplenegative disease and one third had HER2-positive disease. In our study, 48 patients received sequential received taxane-based chemotherapy only. One patient received four cycles of anthracycline-based chemotherapy only and another patient received gemcitabine and vinorelbine. There were 35 patients prescribed herceptin as part of their neoadjuvant chemotherapy.

\section{Tumour size}

After commencement of neoadjuvant chemotherapy, the mean tumour size reduced by more than half, from $4 \mathrm{~cm}$ to $<2 \mathrm{~cm}$. The HER2-positive group showed a relatively greater tumour size reduction to anthracycline-taxane-based chemotherapy and 52 
almost 75\% (Fig). On the contrary, the mean tumour size in luminal A breast cancers remained relatively static despite neoadjuvant chemotherapy.

\section{Nodal status}

More than $80 \%$ of the studied population presented with N1 disease or above. After neoadjuvant chemotherapy, the proportion of patients with N0 disease increased from $15 \%$ to $43 \%$. Just over half (51\%) of the studied group achieved a reduction in nodal staging following neoadjuvant chemotherapy (Table 2). Similarly, patients with HER2-positive disease or triple-negative disease showed a more significant nodal down-staging after chemotherapy $(\mathrm{P}=0.007)$.

\section{Pathological complete response}

Effectiveness of neoadjuvant chemotherapy was determined by the presence of pathological complete response. Pathological complete response was achieved by $23 \%(n=23)$ of patients and $60 \%$ had a partial tumour response. Among these 23 patients, 18 (78\%) had triple-negative disease or HER2-positive disease; oestrogen receptor (ER) status was negative in 14 patients and progesterone receptor (PR) status was negative in 17 patients. Four patients with triple-negative disease or HER2-positive disease had nodal down-staging from N2 or N3. Breast cancers with negative ER status $(\mathrm{P}=0.039)$ or negative $\mathrm{PR}$ status $(\mathrm{P}=0.029)$ had a higher chance of pathological complete response in univariate analysis (Table 3). Other factors including the Ki67 value, tumour grade, and the prescribed chemotherapeutic regimen did not appear to influence the rate of pathological complete response.

\section{Does pathological complete response predict likelihood of breast-conserving surgery?}

Pathological complete response was achieved by 23 patients, of whom 15 (65\%) underwent breastconserving surgery; whereas only $39 \%$ of those with partial or no response had breast conservation. Univariate analysis revealed that patients who had pathological complete response following neoadjuvant chemotherapy had a higher chance of successful breast-conserving surgery $(\mathrm{P}=0.028)$. Mastectomy was required in eight patients despite a pathological complete response due to pre-chemotherapy large tumour size, extensive carcinoma in situ, or central location of the tumour.

Among those with pathological complete response, 11 (79\%) of 14 stage II patients and four (50\%) of eight stage III patients eventually had breast-conserving surgery. Patients with stage II disease showed a trend for more breast-conserving surgery after neoadjuvant therapy although this was not statistically significant $(\mathrm{P}=0.15)$.
TABLE I. Patient characteristics

\begin{tabular}{|cc}
\hline Characteristic & $\begin{array}{c}\text { No. (\%) of } \\
\text { patients* (n=102) }\end{array}$ \\
\hline Median (range) age (years) & $47(25-68)$ \\
\hline Pre-chemotherapy staging & \\
\hline Stage I & $1(1.0)$ \\
\hline Stage IIA & $16(15.7)$ \\
\hline Stage IIB & $33(32.4)$ \\
\hline Stage IIIA & $27(26.5)$ \\
\hline Stage IIIB & $4(3.9)$ \\
\hline Stage IIIC & $21(20.6)$ \\
\hline Mean (range) clinical tumour size (cm) & $4.0(0.5-12)$ \\
\hline Tumour type & \\
\hline Invasive ductal & $93(91.2)$ \\
\hline Invasive lobular & $2(2.0)$ \\
\hline Others (eg micropapillary, mucinous) & $5(4.9)$ \\
\hline Missing data & $2(2.0)$ \\
\hline Hormonal status & \\
\hline ER+ & $59(57.8)$ \\
\hline PR+ & $47(46.1)$ \\
\hline HER2+ & $34(33.3)$ \\
\hline Chemotherapeutic regimens & \\
\hline Anthracycline-based & $49(48.0)$ \\
\hline Addition of taxanes & $35(34.3)$ \\
\hline Herceptin & $(98.0)$ \\
\hline Abbrevions:ER & \\
\hline
\end{tabular}

Abbreviations: ER = oestrogen receptor; HER2 = human epidermal growth factor receptor $2 ; \mathrm{PR}=$ progesterone receptor * Unless otherwise stated

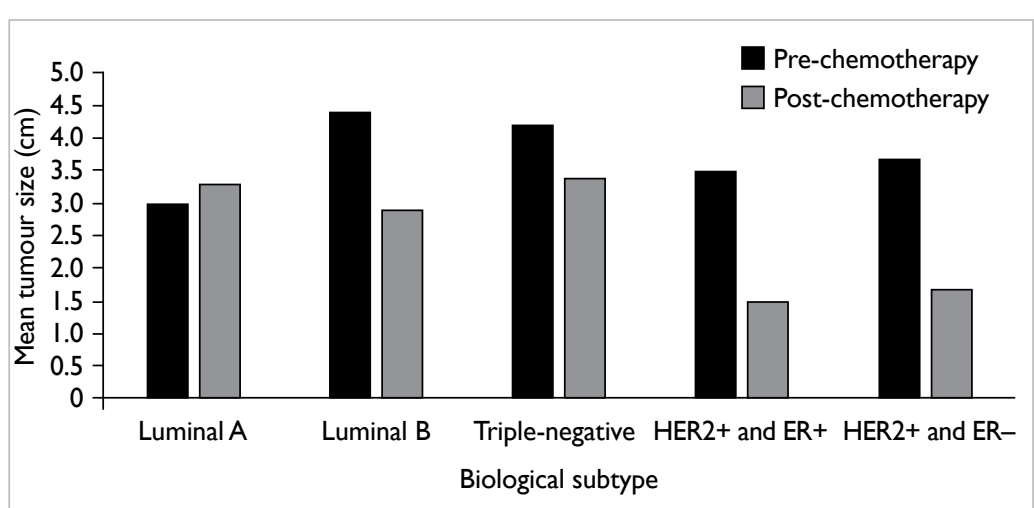

FIG. Changes in mean tumour size after neoadjuvant chemotherapy Abbreviations: $E R$ = oestrogen receptor; HER2 = human epidermal growth factor receptor 2

\section{Feasibility of breast-conserving surgery}

The change of treatment plan after neoadjuvant chemotherapy is shown in Table 4. Before the commencement of neoadjuvant chemotherapy, one quarter of patients $(n=26)$ were scheduled for breast-conserving surgery and three quarters for 
TABLE 2. Change in nodal status after neoadjuvant chemotherapy for different biological subtypes*

\begin{tabular}{lccccc}
\hline & \multicolumn{5}{c}{ No. (\%) of patients } \\
\cline { 2 - 6 } & Luminal A & Luminal B & Triple-negative & HER2+ and ER+ & HER2+ and ER- \\
\hline Down-staging & $3(50)$ & $10(28)$ & $13(52)$ & $14(82)$ & $12(71)$ \\
Static & $2(33)$ & $19(53)$ & $11(44)$ & $3(18)$ & $5(29)$ \\
Up-staging & $1(17)$ & $7(19)$ & $1(4)$ & $0(0)$ & $0(0)$ \\
Total & $\mathbf{6 ( 1 0 0 )}$ & $\mathbf{3 6 ( 1 0 0 )}$ & $\mathbf{2 5 ( 1 0 0 )}$ & $\mathbf{1 7}(\mathbf{1 0 0})$ & $\mathbf{1 7}(\mathbf{1 0 0 )}$ \\
\hline
\end{tabular}

Abbreviations: ER = oestrogen receptor; HER2 = human epidermal growth factor receptor 2

* Data were missing in one patient

TABLE 3. Univariate analysis for pathological complete/partial response

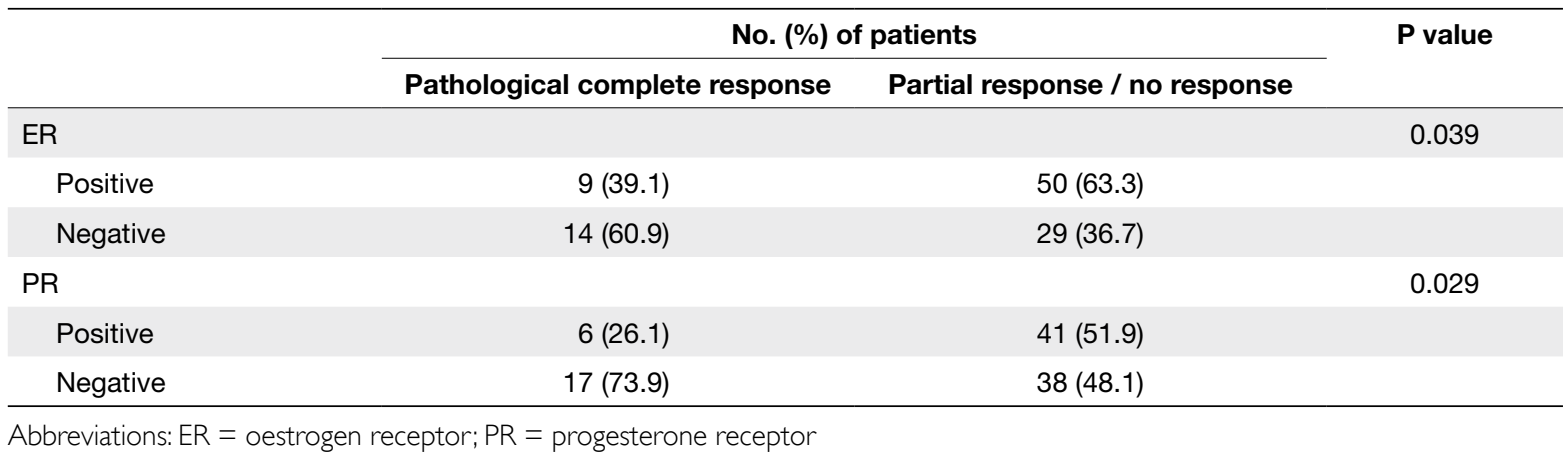

TABLE 4. Change of treatment plan after neoadjuvant chemotherapy*

\begin{tabular}{lcc}
\hline Treatment plan (before $\rightarrow$ after chemotherapy) & Stage II breast cancer & Stage III breast cancer \\
\hline $\mathrm{BCS} \rightarrow$ BCS & 14 & 7 \\
$\mathrm{BCS} \rightarrow$ mastectomy $\dagger$ & 3 & 1 \\
Mastectomy $\rightarrow$ BCS & 18 & 6 \\
Mastectomy $\rightarrow$ mastectomy & 11 & 37 \\
\hline
\end{tabular}

Abbreviation: BCS = breast-conserving surgery

* There were missing data for 4 patients

† One patient had stage I disease

mastectomy ( $\mathrm{n}=72)$. After chemotherapy, one third factors that determined successful conversion to of those scheduled for mastectomy (24 patients) breast-conserving treatment in univariate analysis changed to breast-conserving surgery. The number (Table 5). The breast-conserving surgery to of breast-conserving surgeries increased from 26 to 45 , with an increase of $19 \%$ of all patients.

After neoadjuvant chemotherapy, 24 patients with planned mastectomy underwent breast-conserving surgery and 48 continued with mastectomy. On the other hand, five patients with planned breast-conserving surgery underwent mastectomy after neoadjuvant chemotherapy as a result of disease progression or patient's preference (Table 4). Among the 24 patients with successful conversion from mastectomy to breast-conserving surgery, 21 had tumour size of $<5 \mathrm{~cm}$ and 18 had stage II disease. Pre-chemotherapy disease staging $(\mathrm{P}=0.001)$ and tumour size $(\mathrm{P}=0.005)$ were important breast-conserving surgery. mastectomy ratio in patients with stage II disease was 32:14 patients, ie 2.3 to 1 . On the contrary, 13 patients with stage III disease underwent breastconserving surgery and 38 underwent mastectomy, ie a ratio of 1:3 for stage III disease. Among those who underwent breast-conserving surgery, 93\% had tumour size of $<5 \mathrm{~cm}$. The corresponding proportion in those who underwent mastectomy was $60 \%$. Tumours with size of $<5 \mathrm{~cm}$ were more likely to be amenable to successful breast-conserving surgery. Other factors including the Ki67 index, tumour grade, and the prescribed chemotherapeutic regimen did not appear to influence the rate of 
TABLE 5. Univariate analysis for successful conversion to breast-conserving surgery

\begin{tabular}{lcc}
\hline & \multicolumn{2}{c}{ No. (\%) of patients } \\
\cline { 2 - 3 } & $\begin{array}{c}\text { Conversion to breast-conserving } \\
\text { surgery }\end{array}$ & $\begin{array}{c}\text { No conversion to breast- } \\
\text { conserving surgery }\end{array}$ \\
\hline Tumour size & $21(87.5)$ & $26(54.2)$ \\
$<5 \mathrm{~cm}$ & $3(12.5)$ & $22(45.8)$ \\
$\geq 5 \mathrm{~cm}$ & & \\
Pre-chemotherapy staging & $18(75.0)$ & $11(22.9)$ \\
\hline Stage II & $6(25.0)$ & $37(77.1)$ \\
\hline Stage III & & 0.001 \\
\hline
\end{tabular}

\section{Discussion}

Neoadjuvant chemotherapy was introduced in the 1980 s as standard treatment for locally advanced breast cancers, defined as stage III disease (and a subset of stage IIB disease). ${ }^{5,6}$ In the last decade, the use of neoadjuvant chemotherapy has been extended to patients with early operable primary breast cancers with promising results. The aim of this study was to evaluate the response of early operable breast cancers to neoadjuvant chemotherapy and the predictors of good responders.

Efficacy of neoadjuvant chemotherapy and adjuvant chemotherapy has been carefully evaluated in a number of publications. A prospective randomised trial of the Austrian Breast and Colorectal Cancer Study Group (ABCSG-07) recruited 423 breast cancer patients with stage II to III disease and randomised them to neoadjuvant CMF (cyclophosphamide, methotrexate, fluorouracil) or adjuvant $\mathrm{CMF}^{7}$ The adjuvant CMF group showed superior results in recurrence-free survival, although the OS was similar. Nonetheless, this 'old' chemotherapeutic regimen has now mostly been replaced by anthracycline-taxane-based chemotherapy.

With the emergence of newer chemotherapeutic agents, the National Surgical Adjuvant Breast and Bowel Project B-18 published the largest prospective study with the use of AC (doxorubicin and cyclophosphamide). ${ }^{2}$ Neoadjuvant chemotherapy was at least as effective as adjuvant chemotherapy after a 9-year follow-up. A similar study by the European Organization for Research and Treatment of Cancer published an update after 10 years of follow-up. ${ }^{8}$ There was no difference in OS or relapses between patients with preoperative and postoperative chemotherapy. Those with neoadjuvant chemotherapy had more breastconserving treatment. Further subgroup analysis showed a comparable loco-regional recurrence rate between patients initially allocated to receive breast-conserving treatment and those who did after tumour downsizing. ${ }^{8}$

Meta-analysis of 14 randomised controlled trials that included patients with mostly stage II or III disease showed similar results. ${ }^{9}$ The loco-regional recurrence rate was also comparable between the two groups. There was a statistically significant decrease in mastectomy rate that favoured neoadjuvant chemotherapy.

In our study, patients with stage II to III disease were further stratified in the subgroup analysis. Stage II disease was considered early operable breast cancer while patients with stage III disease represented those with locally advanced disease. This stratification was in line with the MD Anderson Cancer Centre Classification of locally advanced disease. ${ }^{5}$ Patients with early operable breast cancer showed comparatively greater benefits following neoadjuvant chemotherapy in terms of the rate of pathological complete response and breastconserving surgery.

Pathological complete response has been one of the commonly used study endpoints in publications. It has been suggested to correlate with a better long-term outcome. Meta-analysis by Mieog et $\mathrm{al}^{9}$ found improved OS in patients with pathological complete response. The definition of pathological complete response varies from institution to institution, however. In our study, we adopted the definition recognised by the MD Anderson Cancer Centre and in the ABCSG study, ${ }^{10}$ in which there should be no invasive residual disease in breast or nodes although non-invasive breast residuals are allowed. Studies have shown no difference in DFS or OS between patients with ypT0ypN0 and ypTisypN0 tumours.,11

Of note, the rate of pathological complete response appears to be different among various intrinsic types of breast cancer. ${ }^{12}$ In 2005, Rouzier et $\mathrm{al}^{13}$ stratified breast cancer patients into four molecular classes using the genetic profile from a fine-needle aspiration specimen. Patients with basallike and c-erbB2+ breast cancers had the highest rate 
of pathological complete response. Age younger than 50 years and ER-negative status were independent variables with a higher likelihood of pathological complete response. In our study, core biopsies with immunohistochemical staining and proliferation index were used to classify patients into luminal A, luminal B, triple-negative, or HER2-positive subgroups and also showed consistent findings.

Carey et $\mathrm{al}^{14}$ described the phenomenon of triple-negative paradox in 2007. Basal-like and HER2+/ER- subtypes were more chemosensitive than their luminal counterparts. They were more likely to have pathological complete response but those with residual disease also had a higher likelihood of relapse and worse outcome. The study by the German Breast Group in 2012 highlighted the impact of pathological complete response on prognosis in different intrinsic subtypes of breast cancer. ${ }^{10}$ Patients with ypT0N0 tumours had the best DFS $(\mathrm{P}<0.001)$ and a trend of better OS. More importantly, pathological complete response was predictive of DFS and OS in highly aggressive tumours only such as those with negative ER or PR status. Patients with HER2-positive or triplenegative tumours did better if they achieved pathological complete response after neoadjuvant chemotherapy. Residual disease in breast and nodes, on the contrary, was associated with worse distant DFS. ${ }^{15}$

Last but not the least, recent publications have described possible changes in receptor status before and after neoadjuvant chemotherapy although the significance remains controversial. ${ }^{16}$ In our study, change in ER status was evident in $10 \%$ of the study group and that of HER2 in 50\%.

The current study has several limitations. First, this was a retrospective study and the database in the earlier period was incomplete with missing information. There were three patients with significant missing information who were excluded from this small study. Second, there may be selection bias as patients chosen for neoadjuvant chemotherapy were subject to surgeon assessment and patient preference. This study represents the experience of neoadjuvant chemotherapy by one experienced breast surgery specialist in one private hospital in Hong Kong. As such, the findings may not apply to other breast cancer patients in public hospitals or in other countries. Third, long-term survival data are not included in the present study, and significance of pathological complete response is not known. Lastly, the number of cases in this study was small, therefore further subgroup analysis in patients with pathological complete response or successful conversion to breast-conserving surgery was not possible. It does not allow further multivariate analysis for controlling potential confounding factors. Future study in this area with a larger sample size may be useful to guide patient selection for systemic treatment of breast cancer in a neoadjuvant setting.

\section{Conclusions}

Neoadjuvant chemotherapy has expanded indications from treatment of locally advanced breast cancers to render it operable, to downsizing early operable breast cancers enabling breastconserving surgery. The current study has shown an increased rate of breast-conserving surgery with neoadjuvant chemotherapy, especially in the early operable group. Negative hormonal status was an independent variable that determined pathological complete response.

\section{Appendix}

Additional material related to this article can be found on the HKMJ website. Please go to <http:// www.hkmj.org $>$, and search for the article.

\section{Declaration}

All authors have disclosed no conflicts of interest.

\section{References}

1. Hong Kong Breast Cancer Registry Report No. 8. Hong Kong Breast Cancer Foundation. Available from: http:// www.hkbcf.org. Accessed Feb 2016.

2. Fisher B, Brown A, Mamounas E, et al. Effect of preoperative chemotherapy on local-regional disease in women with operable breast cancer: findings from National Surgical Adjuvant Breast and Bowel Project B-18. J Clin Oncol 1997;15:2483-93.

3. Gampenrieder S, Rinnerthaler G, Greil R. Neoadjuvant chemotherapy and targeted therapy in breast cancer: past, present, and future. J Oncol 2013;2013:732047.

4. Thompson AM, Moulder-Thompson SL. Neoadjuvant treatment of breast cancer. Ann Oncol 2012;23 Suppl $10: x 231-6$.

5. Giordano $\mathrm{SH}$. Update on locally advanced breast cancer. Oncologist 2003;8:521-30.

6. Alassas M, Chu Q, Burton G, Ampil F, Mizell J, Li BD. Neoadjuvant chemotherapy in stage III breast cancer. Am Surg 2005;71:487-92.

7. Taucher S, Steger GG, Jakesz R, et al. The potential risk of neoadjuvant chemotherapy in breast cancer patientsresults from a prospective randomized trial of the Austrian Breast and Colorectal Cancer Study Group (ABCSG-07). Breast Cancer Res Treat 2008;112:309-16.

8. van Nes JG, Putter H, Julien JP, et al. Preoperative chemotherapy is safe in early breast cancer, even after 10 years of follow-up; clinical and translational results from the EORTC trial 10902. Breast Cancer Res Treat 2009;115:101-13.

9. Mieog JS, van der Hage JA, van de Velde CJ. Neoadjuvant chemotherapy for operable breast cancer. Br J Surg 2007;94:1189-200.

10. von Minckwitz G, Untch M, Blohmer JU, et al. Definition and impact of pathologic complete response on prognosis 
after neoadjuvant chemotherapy in various intrinsic breast cancer subtypes. J Clin Oncol 2012;30:1796-804.

11. Mazouni C, Peintinger F, Wan-Kau S, et al. Residual ductal carcinoma in situ in patients with complete eradication of invasive breast cancer after neoadjuvant chemotherapy does not adversely affect patient outcome. J Clin Oncol 2007;25:2650-5.

12. Bhargava R, Beriwai S, Dabbs DJ, et al. Immunohistochemical surrogate markers of breast cancer molecular classes predicts response to neoadjuvant chemotherapy: a single institutional experience with 359 cases. Cancer 2010;116:1431-9.

13. Rouzier R, Perou CM, Symmans WF, et al. Breast cancer molecular subtypes respond differently to preoperative chemotherapy. Clin Cancer Res 2005;11:5678-85.

14. Carey LA, Dees EC, Sawyer L, et al. The triple negative paradox: primary tumor chemosensitivity of breast cancer subtypes. Clin Cancer Res 2007;13:2329-34.

15. Corben AD, Abi-Raad R, Popa I, et al. Pathologic response and long-term follow-up in breast cancer patients treated with neoadjuvant chemotherapy: a comparison between classifications and their practical application. Arch Pathol Lab Med 2013;137:1074-82.

16. Pedrini JL, Francalacci Savaris R, Casales Schorr M, Cambruzi E, Grudzinski M, Zettler CG. The effect of neoadjuvant chemotherapy on hormone receptor status, HER2/neu and prolactin in breast cancer. Tumori 2011;97:704-10. 